\title{
UMA ANTROPOLOGIA DE BASE E NA COMUNIDADE: “EU QUERO CRIAR PONTES” - ENTREVISTA COM ESMERALDA MARIANO - MOÇAMBIQUE
}

An anthropology of base and in the community: "I want to create bridges" - Interview with Esmeralda Mariano - Mozambique

\author{
Vera Fátima Gasparetto \\ Doutora em Ciências Humanas pelo Programa de Pós Graduação \\ Interdisciplinar em Ciências Humanas da Universidade \\ Federal de Santa Catarina. \\ gasparettovera@yahoo.com.br \\ http://orcid.org/0000-0002-3865-0549 (i)
}

A lista completa com informações da autora está no final do artigo

\section{INTRODUÇÃO}

Essa entrevista ${ }^{1}$ foi realizada na Universidade Eduardo Mondlane (UEM), no gabinete da antropóloga moçambicana Esmeralda Mariano. Entre suas várias atividades, ela é Diretora Adjunta para a Pós-Graduação da Faculdade de Letras e Ciências Sociais (FLCS).

Ela faz parte dos desafios que temos em contribuir para dar visibilidade e somar na circulação de diferentes conhecimentos no trânsito do "Corredor de Saberes"2 que liga o Brasil e Moçambique, olhando para o ativismo e os estudos de gênero e feministas, os saberes diversos que interagem na realidade local e global, buscando uma relação intercontinental, apesar de marcadores sociais diferenciados, com tendências históricas e relações assimétricas, que tem em comum o estado de colonialidade e o idioma fortemente marcados pela colonização portuguesa (GASPARETTO, 2019).

Em mais de uma hora de conversa, Esmeralda nos levou para vários mundos, os quais ela frequentou ao longo de sua trajetória pessoal, de formação, de docente, de pesquisadora. Sua origem no Centro de Moçambique ${ }^{3}$, seu crescimento no Sul, entre

${ }^{1}$ Realizada em 20 de novembro de 2017, por ocasião do trabalho de campo dentro do Programa de Doutorado Sanduíche no Exterior (PDSE/CAPES). Na transcrição da entrevista optamos por manter a forma de expressão da entrevistada, em português moçambicano.

${ }^{2}$ Via simbólica pela qual circulam conhecimentos produzidos em Moçambique e em África, trazendo essa potência epistêmica para o lado do Atlântico onde está o Brasil e a América Latina.

${ }^{3} \mathrm{O}$ território de Moçambique, a partir da Conferência de Berlim (1884/5), está localizado no sudeste do continente africano, na África Austral. A independência de Moçambique do jugo colonial 
Changanas, seu casamento com um italiano, que a levou morar e estudar na Itália, onde fez sua graduação em Letras e Filosofia, com orientação Etno-Antropológica (Universidade de Gênova), seu mestrado em Antropologia Social (com enfoque em Ecologia Humana), pela Universidade de Bergen, Noruega, e seu Doutorado em Antropologia Social e Cultural, pela Universidade Católica de Leuven, na Bélgica ${ }^{4}$. Ou seja, uma mulher do mundo.

$\mathrm{Na}$ minha investigação de doutorado, realizada em 2017, busquei ouvir de Esmeralda sua visão acerca de um feminismo africano/moçambicano: "Existem vários feminismos moçambicanos, existem teóricas feministas africanas, existem vários feminismos". Da sua experiência globalizada, ela fala da importância do trabalho de campo, da relação com as comunidades locais, de uma antropologia engajada e crítica, da dicotomia entre ser acadêmica e ativista e a sua busca por um entre lugar.

Foi um diálogo, uma conversa, uma troca, para trazer um pouco do seu pensamento sobre gênero e sexualidades, tradição e modernidade, o papel das intelectuais na investigação, o lugar do local nas estratégias de desenvolvimento, seu olhar sobre a perspectiva epistemológica moçambicana/africana e os necessários diálogos entre o local e o global. Tudo isso a partir das suas experiências, que trazem outros saberes para a agenda de pesquisa.

Confira a potência da sua voz e pensamento.

\section{QUESTÕES E RESPOSTAS}

Agradeço muito que você me receba e além da minha vontade pessoal em te conhecer, você foi muito bem recomendada pela professora Miriam Grossi (UFSC). A primeira questão é sobre sua trajetória, de como que escolneu o caminho da antropologia, suas motivações objetivas e subjetivas, e dentro desse caminho como surgiu o campo de gênero nos teus estudos?

Esmeralda Mariano - É um percurso um pouco longo, não é? Muitas vezes nós não pensamos que já temos quase um percurso definido na nossa vida e vamos costurando, delineando e aprimorando esse percurso. Então na antropologia eu iniciei os meus estudos

português ocorreu em 25/06/1975, após 10 anos de luta armada, liderada pela FRELIMO. Após decorreram mais 16 anos de guerra civil, com cessar-fogo negociado em 1992. A população do país é de 28.861.863 habitantes, a imensa maioria de jovens, 52,19\% mulheres, e $65 \%$ da população vivendo no meio rural (GASPARETTO, 2019).

${ }^{4}$ Para conhecer mais, sugiro a entrevista concedida a Pimenta e Moutinho (2017). 
acadêmicos em 1992, eu estava em Itália. Eu sempre gostei de estudar, talvez recuar um bocadinho na minha história pessoal e familiar. Eu sou produto misturado (sou negra, mas tenho misturas lá no meio que não o que são: de raça, etnia, categorias complexas e indefinidas) e isso puxa o meu interesse em compreender e aceitar a diversidade. Acho que esse é um pressuposto básico que bebi dentro da minha família. Eu sempre vivi num meio multicultural e muito misturado. Eu nasci e cresci até aos 16 anos na Beira (Centro do país), os meus pais são naturais de outra província (do Sul). Mas em casa predominava a cultura do Sul (dos progenitores), pois mantivemos sempre a relação com a família (avós e tias). Alguns de nós [irmãos/ãs] ficam numa situação nem tão do Centro (por que não convivíamos muito com as pessoas do centro), nem tão do Sul (por que também não tínhamos uma vida cotidiana com as pessoas do Sul). Meus pais falavam entre eles em língua Changana, mas eles preferiam que nós apreendêssemos e falássemos português, por causa da política da assimilação, eles estavam convencidos que teríamos mais sucesso na escola e na vida. Mesmo assim, nós captávamos a língua materna. Eu aprendi a falar Changana de crescida, por necessidade, e aprimorei com o trabalho de investigação. Quando eu estava na Itália senti um desejo muito grande de manter uma ligação com minha cultura de origem. Eu queria estudar e entrei para a Universidade, escolhi ciências sociais, escolhi antropologia. Falei por acaso com um padre amigo nosso, Ezequiel Guembe [falecido em 2016], que também era antropólogo (um dos poucos antropólogos moçambicanos da época), depois da independência. Ele me disse "Por que não fazes antropologia?", e eu senti que tinha uma grande afinidade por essa área de interesse. Na minha família a hibridez faz parte da nossa vida, meu avô materno era um conhecedor de ervas medicinais, também era enfermeiro, e professor primário. Nós na família misturávamos de forma idiossincrática, vivendo essas misturas entre a tradição e o moderno, convívio de momentos um pouco conflituosos, outros da forma mais pacífica, mas sobrepõem-se as diferentes lógicas no nosso modo de estar. Meu avô era também polígamo (casou com muitas mulheres). Era uma poligamia, no nosso entender, organizada e estruturada, porque ele conhecia e reconhecia todos filhos e filhas, e as mulheres que viviam no mesmo espaço. Esses tantos elementos, que vivendo num outro mundo, me levaram a pensar na poligamia (uma prática tão criticada), minha mãe que teve oito filhos, mas que também queria ser uma mulher emancipada, porque bebeu os ventos dos anos 1960, e esteve em contato com ideais feministas da época. Ela não tinha formação superior, mas era culta, lia muito, era muito curiosa e de espirito inquisitivo. O pai dela ouvia a rádio Tanganica (no início da luta armada) e convidava os filhos a prestar atenção aos noticiários 
sobre as independências africanas. Minha mãe era também uma militante e isso influenciou na nossa maneira de ser e de estar. Ela sempre quis, desde o pai lhe dizia "Olha Ludovina, tu vais para o Norte". O Norte não se referia à localização geográfica, a cidade da Beira, para onde ela foi depois de casada, mas referia-se ao mundo, a abertura ao mundo, algo que interiorizei, por isso estou a partilhar consigo, e acho que é muito forte! Minha mãe e meu pai sempre quiseram que todos os filhos estudassem, mas minha mãe, em particular, era uma personagem muito forte. Tanto é que isso abriu a maneira de nós estarmos na nossa família, de superar as barreiras raciais, a conviver com todas as raças. Então essa abertura também fez que nos sentíssemos abertos, tanto é que os filhos viajam, vivem e convivem com pessoas dos vários cantos do mundo.

\section{E sobre a motivação subjetiva, como você as observa na sua trajetória?}

Esmeralda - A motivação subjetiva vem da própria experiência de vida. Em casa, onde comecei a interessar-me pela antropologia, e a formação em Antropologia na Itália. Durante a formação vim pra Moçambique fazer o tralho de campo. Escolhi o lugar de pesquisa, e foi tudo uma série de coincidências, talvez, um local que é da origem da minha mãe, dos pais dela, dos Tembe. KaTembe, na zona de Matutuíne. A pesquisa era sobre concepções inerentes à fertilidade feminina e a terra, aspectos simbólicos da questão entre a mulher e a terra. A pesquisa abordava questões de saúde e doença, e trabalhei também com os curandeiros. Talvez isso puxei do meu avô. Na adolescência sonhava ser médica, mas não consegui por várias razões. Em 1982 saímos forçados da Beira para viver em Maputo. O sonho de fazer medicina foi interrompido, mas fiz antropologia com enfoque na área da saúde. Quando terminei a licenciatura com o tema sobre "infertilidade", de alguma maneira comecei a interessar-me e a tratar das questões de saúde. Em contato com a Faculdade de Medicina, da Universidade Eduardo Mondlane (UEM), convidaram-me a colaborar com o Departamento de Saúde da Comunidade, no âmbito de um programa de formação que a Faculdade de Medicina tinha com a Noruega (Programa NORAD) ${ }^{5}$. Nesse período consegui uma bolsa de estudos para fazer Mestrado em Antropologia Social com enfoque em Ecologia Humana, onde pude aprofundar elementos teóricos e metodológicos sobre saúde, doença e ecologia, e começar a compreender as questões de gênero. Quando terminei o mestrado, vim para Moçambique, continuei a colaborar com a faculdade de medicina dando algumas aulas, enquanto definia minha trajetória na academia. No

${ }^{5}$ Sigla em inglês da Agência Norueguesa de Cooperação para o Desenvolvimento. 
programa curricular da formação médica as disciplinas das ciências sociais não estavam incluídas. Participei no desenho da proposta do Mestrado em Saúde Pública, onde introduzimos uma disciplina de antropologia, que mais tarde foi extinta. Há alguma resistência ou relutância por parte da biomedicina em constituir uma disciplina de Antropologia nos cursos de graduação e pós-graduação, mas há um desenvolvimento e uma maior abertura, nos dias de hoje, às ciências sociais.

\section{Nos teus trabalhos de pesquisa, qual você considere que teve maior impacto acadêmico e social?}

Esmeralda - Eu trabalhei numa pesquisa da Organização Mundial da Saúde (OMS) a convite de uma amiga francesa [Brigitte Bagnol], sobre gênero, sexualidade e práticas vaginais $^{6}$. Depois da minha formação, com o trabalho de campo começo a aprofundar minha compreensão e análise sobre as relações de gênero, a informar-me sobre os debates em torno e as várias perspectivas teóricas sobre gênero. É um estudo grandioso que foi feito, comparando quatro países: África do Sul, Moçambique, Tailândia e Indonésia. Moçambique foi o país que produziu dados particulares e ricos, pois fizemos uma combinação de métodos. Iniciamos com a etnografia de imersão no campo, em seguida inquéritos quantitativos numa amostra representativa na Província de Tete, envolvendo 919 mulheres. No estudo etnográfico, o nosso objetivo era trazer uma perspectiva êmica, uma perspectiva das mulheres, o ponto de vista das mulheres. E nesse exercício, a visão das mulheres entra de alguma maneira em contraste com a esfera política, aquilo que é o discurso político, comum e retórico das instituições, como da própria OMS, com a perspectiva dos direitos humanos, dos direitos sexuais e reprodutivos das mulheres. Por que algumas das práticas sexuais na perspectiva ethic, ou perspectiva objetiva, são vistas como práticas nocivas, quando as mulheres, nossas interlocutoras, não viam as implicações dessas práticas sobre seus corpos e sua saúde, sua saúde sexual, o prazer e outras dimensões, que normalmente não são abordadas.

É um exemplo de como a perspectiva hegemônica da produção científica constrói suas análises. $O$ que isso nos diz sobre essas políticas, há uma imposição de uma visão que satisfaz as instituições financiadoras?

\footnotetext{
${ }^{6}$ Ver artigo "Cuidados consigo mesma, sexualidade e erotismo na Província de Tete, Moçambique" (BAGNOL E MARIANO, 2009).
} 
Esmeralda - Sim. Eu e minha colega nos mantivemos na perspectiva de ver o agenciamento da mulher, o lado positivo da sexualidade, particularmente, os espaços onde a mulher tem o poder através do controle do seu corpo. Não só olhar o corpo controlado politicamente pelas instituições, mas observar e entender um corpo que também tem uma agência. Um corpo que encontra no meio das grandes teorias como vítima passiva...não queremos dizer que este corpo não seja também vítima de violência, não seja um corpo que também interfere outras lógicas e outras forças de dominação, mas é um corpo que de alguma maneira tem uma voz, tem um espaço de prazer. Então, nessa etnografia, não trazemos uma análise crítica às práticas em si, mas procuramos chamar atenção sobre a necessidade de desconstruir e desmitificar alguns conceitos, olhando por exemplo, para os nomes atribuídos, categorias e classificações referidas como mutilações genitais femininas pela OMS. Em 2008 a OMS repensa e redefine outras classificações e terminologias, fruto da contribuição também do nosso estudo. Falar de modificações genitais, em vez de mutilação. Trago como exemplo uma das práticas muito difusas, realizadas por quase $90 \%$ das mulheres na Província de Tete, que é o alongamento dos lábios vaginais, que não é uma mutilação, mas é uma expansão. Pode ser uma deformação, se quisermos, mas do ponto de vista de quem? Para as mulheres de Tete essas práticas são vistas como um componente estética, como um elemento que proporciona prazer. Assim como as mulheres no Ocidente acham que não fica bem ter os lábios mais alongado naturalmente, e fazem as cirurgias de redução. Porque o alongamento dos lábios vaginais não é para fins terapêuticos, considerada tradicional, portanto não se encaixa nos critérios da OMS, para quem todas as práticas que não tenham finalidade terapêutica são consideradas invasivas. Os resultados do nosso estudo suscitaram bastantes debates, críticas e controvérsias.

Primeiro, por que para alguns era visto como se estivéssemos a sustentar práticas que põe a mulher numa situação de subordinação. Práticas que são consideradas tradicionais e que tinham toda uma história de subordinação feminina, desde a luta de libertação pela independência do país, da emancipação da mulher, onde as práticas vaginais foram condenadas e vistas como formas de violência contra a rapariga e mulher, ao invés de emancipar a mulher, tornam-na mais submissa e com pouco poder de controle. Nós vimos que não é exatamente assim. É interessante por que algumas autoras, como a Signe Arnfred, pega nesses discursos, analisa de forma crítica. É verdade que é preciso sermos cautelosas, para não exagerar na rigidez do fraco poder da mulher, mas sim um corpo que procura e tem um espaço, uma mulher com agenciamento. 
A Signe Arnfred aponta que esse é um espaço de poder, no caso esse agenciamento que você identifica, esse controle e decisão sobre o próprio corpo.

Esmeralda - Ela considera um espaço de poder que a mulher tem, dialogando com o que nós identificamos. Ela é uma figura de referência por que acompanhou várias fases e épocas históricas, precisa ler ela, por que trabalhou com as mulheres da Organização da Mulher Moçambicana (OMM), nas cooperativas com mulheres, conhece muito bem as políticas de desenvolvimento depois da independência, acompanhou os debates e os processos de emancipação da mulher, particularmente, no norte de Moçambique. Ela faz uma evolução do seu pensamento, não na lógica radical, pois tem uma postura mais aberta de perceber as nuances das práticas, da sexualidade e das dinâmicas políticas e sociais. A ideia de fundo é que não se pode sempre afirmar a vitimização da mulher, mas parece mais produtivo procurar espaços de negociação e de afirmação social, até como uma estratégia positiva para o próprio empoderamento da mulher.

\section{E foi esse estudo que te despertou a questão de gênero?}

Esmeralda - Sim, por que para o desenvolvimento do estudo fizemos diversos debates com investigadoras e cientistas de várias partes do mundo, o que nos permitiu perceber as diferentes teorias e os vários estudos que já haviam sido feitos. De uma forma mais sistemática, este estudo permitiu-me olhar outras experiências: pessoais, familiares, para melhor visualizar as representações em torno do próprio estudo, assumindo uma posição relativista, mas não acrítica. Sabemos que existem implicações objetivas de algumas dessas práticas, implicações para a saúde do ponto de vista médico. Mas, também na lógica de risco, as camadas ou níveis de riscos que as pessoas têm ou têm que assumir, é negociável. O corpo é um espaço de poder importante que as mulheres têm através dos quais reproduzem algumas dessas práticas. É um espaço de afirmação, de construção da própria identidade feminina.

A decisão sobre esses ritos de transformação do corpo alcançaria questões relacionadas aos ritos de iniciação e outras práticas chamadas tradicionais? Estas também criticadas por um feminismo exógeno, que olha para cá como um lugar que não tem agência e as mulheres são vítimas? Que outros temas entrariam nesse debate? 
Esmeralda - Eu primeiro ia dizer que cada vez mais somos chamadas a prestar mais atenção às terminologias que usamos, por que se pensarmos no próprio conceito de "rito", eu preferia começar a usar "escolas de iniciação" ou "escolas de aprendizagem". Elas estão tão institucionalizadas que são escolas. Nelas existem vários tipos, grupos de mulheres, há um processo de socialização, de troca de conhecimento e experiências (assim como se espera que seja numa universidade). Temos várias instituições, até mesmo igrejas. Como é que essas instituições trabalham? Eu cada vez estou mais cética em relação a essas definições e a esses campos. Nós temos muitos campos separados, mas que é preciso ver de forma interligada, pois neles nem sempre existem fronteiras rígidas. A igreja tem um papel influenciador, controlador dos corpos e mente. Depois temos a escola, a família, e é preciso ver quais são as dinâmicas dentro desses espaços, olhar para esses vários aspectos de forma mais fluída, e não de forma estanque, fixa. Quando falamos de agência feminina também temos que pensar nisso para evitar alguma forma de exotização e também para reduzir essa tendência do nosso olhar estereotipado sobre as mulheres. Quer dizer, refletir o nosso conhecimento sobre o ponto de vista das mulheres, evitando o máximo possível a distorção. Não sei...Metodologicamente e epistemologicamente um exercício complexo. Aliás a ideia de pureza, sempre questionável...

\section{Seria não colonizar os pensamentos dessas mulheres? Eu consigo compreender que elas nos propõem uma nova nomenclatura ou novas formas de pensar ou repensar essas categorias...}

Esmeralda - O repensamento dessas categorias eu acho que é muito importante. Também para evitar mapeamentos teóricos abstratos, descontextualizados, que não refletem na maior parte das vezes a realidade, não é? Pensando, por exemplo, naquilo que eram as ideologias de emancipação depois da independência: "vamos eliminar as práticas tradicionais, abaixo!". Essas práticas continuam até hoje, manifestas de formas diferentes, com formatos diferentes, mas estão até hoje. Apesar de todo o esforço dedicado, de toda a força que a Frelimo [Frente de Libertação de Moçambique] empreendeu, depois da independência, o empenho em eliminar, erradicar todas as formas e práticas tradicionais consideradas retrógadas, nefastas, tribais e étnicas, nem sempre foram alcançados.

Ouvi que setores da OMM não concordavam com a forma como os homens da Frelimo e o próprio Samora Machel utilizavam para acabar com essas práticas. Elas 
propunham uma negociação dessas transições, diálogos com os grupos étnicos, mediações.

Esmeralda - É isso mesmo, e até hoje temos que pensar em termos de negociação, por que nós não estamos a usar, por que as práticas estão presentes até hoje e foram "eliminadas". Se o alongamento dos lábios era feito no período colonial, continua até hoje, como uma intervenção sobre o corpo essencial para a identidade da mulher.

Para aquela comunidade essa prática é muito importante. Seria por que cria um pertencimento?

Esmeralda - A ideia do pertencimento, exatamente! Pode não ser dita, e é essa uma das questões presentes nas discussões que tivemos com médicos, juristas, ativistas sociais, que estavam sempre falando da eliminação. Depois de passados 30 anos do discurso de Samora, de tudo o que aconteceu, ainda se discute por que estão lá, por que são feitas estas práticas por jovens mulheres do meio urbano e rural. Eu me lembro quando fizemos o estudo, nos encontros em instituições públicas, e explicávamos da gama de produtos que as mulheres utilizam e ainda hoje usam nos cuidados das suas vaginas, para atrair o homem, para manter o homem, para uma melhor performance sexual... Quando falávamos sobre o assunto nas instituições, as mulheres presentes diziam: "ah isso é interessante!"... Queriam! (Fala com ênfase). Tinham uma série de reservas, mas ao mesmo tempo queriam conhecer, experimentar e diziam: "eu também quero o produto" (risos).

\section{No mundo ocidental cada vez mais são procurados sex shop, adereços,} acessórios para aumentar o prazer sexual.

Esmeralda - Exatamente! No contexto que referimos creio que há produtos que são abrasivos, produtos que são nocivos. Algumas mulheres falavam da descamação da flora vaginal, explicavam os efeitos colaterais, mas continuavam. Mas também sabemos que tem tantas coisas que são produzidas, comercializadas e que botamos na nossa pele, no nosso cabelo. Continuamos a experimentar cremes que nem sempre sabemos a composição e os efeitos. Mesmo nos frascos que são vendidos as letras são minúsculas para impedir a nossa real percepção. Por que há um negócio, há um comércio, há outros interesses da mercantilização do corpo e da vida, há necessidades e finalidades que nos levam a fazer uma determinada prática. Não estou a dizer que devemos ficar às cegas, é importante um conhecimento, mas é um processo de negociação. 
Você chega num ponto central nesse debate sobre o que é endógeno e o que é exógeno na construção do conhecimento local. Qual a sua opinião sobre a contribuição, ou não, da chamada indústria do desenvolvimento para dizer qual prática que é válida e qual não é? Assim o que seria o "desenvolvimento" a partir das realidades cotidianas?

Esmeralda - Eu penso que qualquer desenvolvimento precisar ser localizado e combinar a percepção local sobre algo, sobre algum conhecimento e fenômeno, em articulação com outras formas, lugares e tempos. Por que nós bebemos...e eu contei a minha história: "eu não sou um produto puro, eu sou um produto misturado, híbrido, um produto que vai absorvendo e se definindo". E na história de Moçambique temos tantos elementos que somos e fomos agregando, e que depois chamamos "nossos produtos", que são incorporados, por que são produtos de propriedade nossa - a própria capulana. A proposta da capulana, por exemplo, no meu estudo eu falava do tecer das relações e o processo de entrelaçamento, pegando no casamento entre famílias internas e famílias externas. Há um elemento que une, um símbolo fundamental nas transições e transações de uma mulher que sai de um lugar para outro lugar quando se casa, que é feita a partir da capulana, mas chamava-se no sul de nthee (contaram-me as minhas tias maternas). Quando ainda não existia a capulana, usava-se a pele de um animal curtida para pôr o bebê nas costas. O chamado nthee era uma peça de valor importante, por que é ali onde você cresceu, é como se fosse uma incubadora. O nthee tem um valor até no sentido da formação do próprio indivíduo, por isso era utilizado e passado para outras gerações. Atualmente não é o próprio material, mas o símbolo da capulana, por exemplo, no lobolo 7 . Tem, que dar a capulana à tia, à avó, por que foi aquela que cresceu. $\mathrm{O}$ homem, por exemplo, vai casar com uma mulher que foi criada e educada com um nthee. $O$ que quer dizer? Que é para ficar junto, união. Esta é a ideia, criação de redes sociais, familiares, são relações que vão multiplicando, que vão sempre atando, sem desligar completamente.

Isso para dizer que a lógica do desenvolvimento precisa ser dar de uma forma articulada, negociada, fluída, e sem imposição e supressão de outras lógicas e saberes. Nós sabemos quais são os limites das imposições. São muros, são barreiras, e para cada um de nós a informação é fundamental. Se eu falo de um nthee ou da capulana, o

7 Lobolo é a palavra local para designar "o preço da noiva", um ritual que predomina do Sul de Moçambique, no qual a família da noiva é recompensada economicamente pela passagem da mulher e dos seus filhos para a família do marido (GASPARETTO, 2019). 
significado profundo desses elementos é que nos permitem falar e pensar como é que nós podemos "usar" um conhecimento, não na ótica utilitarista, mas apropriar-nos desse conhecimento, torná-lo inteligível, acessível, compartilhado, por que faz parte da cosmovisão. Faz parte de uma lógica que pode contrastar a ótica desenvolvimentista, que define previamente as regras sem conhecer o contexto.

Não vai se encaixar por que há uma barreira em termos de conhecimento e aproximação de interesse por um conhecimento. No processo da minha formação, dialoguei com médicos da biomedicina (ginecologistas), enfermeiros, com os médicos tradicionais, com e mulheres - pacientes, e rapidamente notei que as ciências sociais e as ciências naturais ainda são campos disciplinares entre si incomunicáveis. Para entender os processos de desenvolvimento, para garantir um crescimento é preciso dialogarmos, entendermos várias linguagens, para as quais uma abertura e uma aproximação são de uma riqueza. $E$ depois para percebermos a funcionalidade e como é que as estratégias de desenvolvimento podem ser efetivamente construídas com alguma eficácia e algum benefício para todos. Acho que é um processo estabelecermos a comunicação, e um desafio encontrar a chave de como é que esta pode ocorrer.

\section{Você percebe nas agendas de pesquisa uma influência dessa indústria do} desenvolvimento e a priori um resultado aonde se quer chegar?

Esmeralda - Com certeza. Não há dúvida nenhuma. Nós pegamos na pesquisa que é o nosso campo, aqui na academia, como investigadora, a pesquisa é a chave, informa as lógicas e as óticas de desenvolvimento, informa as políticas públicas. Então, as próprias relações a nível mundial, entre países, são definidas por agendas políticas que muitas vezes não são completamente resultado de consensos, de desejos compartilhadas e mutuamente percebidas. São baseadas em lógicas de alguma maneira de supremacia, onde as relações de poder são assimétricas e as definições das próprias agendas de pesquisas não são de acordo com o que é o interesse local. Aliás, o interesse global tende a ofuscar o local, para benefício próprio. Um exemplo que vou dar, da minha pesquisa de doutoramento, sobre a infertilidade feminina. Infertilidade é um tema preocupante, e desde a Conferência Internacional para a População e o Desenvolvimento, em 1994, definiu-se como uma das linhas prioritárias a infertilidade no campo do planejamento familiar. Mas a infertilidade aqui em Moçambique, passados quase 30 anos, ainda não faz parte da prioridade da política nacional de saúde sexual e reprodutiva, por que nós temos outras prioridades mais urgentes. A questão é: quem define quais são as prioridades? Mulheres e 
homens inférteis não constituem uma prioridade nas políticas de saúde. Quem tem recursos financeiros, uma minoria, tem acesso ao turismo médico na vizinha África do Sul ou ainda, opções em viagens continentais.

\section{Pelo contrário, eu ouvi uma fala que um dos grandes problemas de} Moçambique é a alta taxa de fertilidade.

Esmeralda - Tem que ver quais são as perspectivas disciplinares que enfatizam a fertilidade como um problema. Se quiser podemos discutir sobre isso. A teoria Malthusiana na lógica do desenvolvimento, se nós reduzirmos a natalidade, pode ter sentido objetivamente, mas a fertilidade também precisa ser vista do lado subjetivo. Também no meu estudo é um paradoxo: precisamos entender por que a fertilidade é muito alta e constitui um problema? Qual é o valor que é atribuído à fertilidade? Se é dado um valor muito alto à fertilidade, imagina o que significa a infertilidade na perspectiva do indivíduo. $\mathrm{E}$ é preciso perceber como é que essas mulheres se tornam inférteis, pois uma das principais causas da infertilidade na África Subsaariana são as doenças sexualmente transmissíveis (DSTs). E isso não se toma em conta, como o caso da gravidez precoce, que pode igualmente ser causa da infertilidade (ainda que secundária). Há um ciclo vicioso, e é preciso entender isso, mas infelizmente o tema da infertilidade não tem a devida atenção nas políticas de saúde. Ao contrário, nos países desenvolvidos a infertilidade tem uma atenção especial, também por que responde ao desenvolvimento da ciência médica, às tecnologias reprodutivas, interesses econômicos e a medicalização da infertilidade. Prevalece o paradoxo da quantidade de dinheiro que se investe nas novas tecnologias reprodutivas, inseminação artificial, dos bebês de proveta. Se estamos a falar de um mundo global, onde se situa Moçambique em relação a isso, para além do fato de que as mulheres até podem conseguir conceber muitos filhos, mas por que que as mulheres têm muitos filhos em muitos contextos pobres? É segurança social, é um meio de garantir que dos cinco filhos, por exemplo, pelo menos dois sobrevivam à mortalidade infantil, que é muito alta. Então todos esses elementos precisam ser repensados e não apenas definir o planejamento familiar, sem ter em conta as experiências individuais e os contextos específicos na aplicação de políticas globais. As tecnologias reprodutivas têm sido exportadas para várias partes do mundo, porém ainda é restrito só para segmentos de elite da sociedade. 
Por isso, a infertilidade entrou no quadro das estratégias de planejamento familiar, incluída na agenda de saúde reprodutiva, com a ICPD em 1994. Existem atenções preventivas da infertilidade, mas por que a medicina não é tão preventiva como seria desejável, no nosso contexto é mais curativa, e no caso da infertilidade a prevenção e cura são limitadas. Também é preciso perceber quais são as lógicas das políticas públicas, como são definidas as áreas onde dar mais atenção: à cura ou a prevenção, por que estrategicamente implica a criação de condições. O ideal seria uma menina não ter filho aos 15 anos, não engravidar "precocemente" por que tem riscos, mas sim construir condições para ela continuar os seus estudos. Mas, vá lá para lugares recônditos de Moçambique, que não tem energia elétrica, não tem uma escola secundária ou superior para as meninas e meninos continuarem a estudar. Que opções têm as crianças após terminarem o $11^{\circ}$ ano? O que fazem se não tem outras condições? Que sonhos podem ter? Eu me lembro em 2004 fizemos uma pesquisa na província de Tete e perguntamos aos jovens: quais são os seus sonhos? Não tivemos resposta. Como é que um jovem com limitadas condições pode ter e manter sonhos para além daquele de dizer que quero casar quando acabar a $11^{\mathrm{a}}$ classe.

Quando criança, meu filho - a partir das imagens que a mídia escolhe nos mostrar da África como catástrofe, calamidade, desgraça - me perguntou "por que as pessoas aceitam isso?"

Esmeralda - É verdade que é preciso resistir, ser mais resiliente, é preciso lutar.

Mas a pessoa não sabe, ela não tem acesso a um horizonte. Ela até pode sonhar, mas ela pensa que não existe.

Esmeralda - Mas vai sonhar o que? Vai sonhar para aquele horizonte que ela já conhece.

Você considera que esses estudos e trabalhos realizados por acadêmicas e pesquisadoras da WLSA e outras configuram um campo dos estudos de gênero em Moçambique?

Esmeralda - Eu penso que já se configuram nos estudos de gênero os vários trabalhos que têm sido feitos. Falo pela discussão que tenho com colegas na academia, Cairo.

\footnotetext{
${ }^{8}$ Sigla em Inglês para Conferência Internacional sobre População e Desenvolvimento, ocorrida no
} 
em particular no meu Departamento. Nós temos linhas de pesquisa, perspectivas de pesquisas. Por exemplo, algumas são aquelas consideradas ativistas (de intervenção social) e outras são mais acadêmicas (teóricas). E parece-me que há uma barreira, há fronteiras que estão delimitadas. Eu pessoalmente me situo entre as duas. Quero me sentir entre as duas, o que é um problema, por que a academia sente-se na prerrogativa de ser só acadêmica, pesquisa pura, como sendo aquela que tem valor científico e reconhecimento. Por que mesmo que eu tenha feito pesquisas, por exemplo, por "encomenda", ou pesquisas impostas, pesquisas que não são definidas ou concebidas por nós, produzimos algum conhecimento, participando nessas pesquisas podemos dar a nossa contribuição, influenciar a nossa perspectiva, a nossa visão. Podemos construir uma perspectiva que espelhe a realidade, sem distorções. Eu acho que é possível, e nós fizemos isso com o estudo que mencionei. Em parte não era só responder uma agenda, por que o fato de estarmos ligadas e termos tido a cobertura de uma instituição tão importante como a OMS pode parecer que nós estivemos amarradas a um quadro, a perspectivas que não nos deixam espaço. Pelo contrário, pelo menos durante o processo, e depois do processo de pesquisa, tivemos tempo e espaço para a reflexividade, de compreender e assumir uma posição crítica. Fizemos ao mesmo tempo pesquisa, ação e militância. O estudo foi feito entre 2004-2007, ainda hoje continuamos a discutir e analisar, com elaboração de vários artigos, trazendo questões do estudo, mas também outras estudiosas reanalisam o trabalho para ver onde estão os espaços de poder feminino. Quais são os discursos que são construídos em diferentes ângulos, visões e perspectivas. Nós podemos pensar que estudos de gênero estão sendo construídos, sim, em Moçambique. Se nós pensarmos desde a independência qual era a visão que as jovens tinham sobre gênero, sexualidade... E é preciso perceber que não há uma produção tão vasta mas há uma discussão, há um sentimento sobre a necessidade de se estudar mais.... Talvez precisamos trabalhar ainda mais... trabalhar mais na teorização, mas eu tenho algumas reticências em relação às teorizações. É verdade que as teorias dão um certo reconhecimento e uma certa validade, isso também pode estar a faltar de alguma maneira.

\section{E como se organiza, na sua percepção, esse campo dos estudos de gênero e}

\section{feminismo em Moçambique?}

Esmeralda - Existem vários grupos de homens e mulheres que se dedicam de forma ativa a investigação sobre questões que tocam homens e mulheres, para o empoderamento e emancipação das próprias mulheres e dos homens. Existem também grupos de 
investigadores que desenvolvem estudos baseando-se até em análises críticas das primeiras correntes dos estudos feministas. Particularmente crítica é a desconstrução das perspectivas teóricas ocidentais. Existe esse engajamento por parte de acadêmicos em Moçambique, e existe um outro grupo mais engajado de forma ativa, fazendo intervenções que pode se enquadrar no ativismo, e esses são os grupos de feminismos que vemos aqui em Moçambique. Infelizmente ainda não estão a trabalhar de forma articulada no que se refere a uma ligação entre o espaço acadêmico e o espaço de ativismo.

Acho muito interessante o que você traz, pois tenho tentado compreender os motivos dessas lacunas, dessas barreiras e fronteiras que delimitam esse campo dos estudos de gênero, onde algumas mulheres e homens se identificam como feministas (mas não militantes). A algumas dizem "eu sou feminista militante e não acadêmica". Outras são como você: "eu quero estar entre os dois". Como pensar uma metodologia de intersecção e diálogo para construir uma outra academia, considerando que na academia que temos há pouco espaço para isso?

Esmeralda - Eu não sei muito bem como superar esse dilema. Vocês no Brasil têm uma longa experiência, uma longa caminhada, maior que a nossa. Nós já temos alguns elementos para refletir e pensar porque já temos consciência das limitações de algumas perspectivas teóricas e do desenquadramento de algumas perspectivas teóricas que usamos nas nossas análises, e que algumas delas fazem pouco sentido, mas ainda falta essa reelaboração e mais construção teórica que seja um marco. Isso falta aqui. Estamos num bom caminho, num processo, porque somos poucas pessoas, isso não é justificativa, mas ainda precisamos desmembrar de alguma maneira...[silêncio]...talvez ainda estejamos amarradas aos cânones estabelecidos. Para ter um reconhecimento, um valor científico é preciso tu teres referências teóricas, tu te posicionares em relação a uma referência teórica. Por outro lado, temos o lado prático ou aplicado do conhecimento. O que eu quero fazer é retro informação. Quando estou na academia já estou a transmitir, talvez ai esteja a dar a resposta, metodologicamente como podemos fazer. As pesquisas que nós realizamos, que geralmente tem a ver com questionamentos que temos sobre a realidade, sobre os fenômenos sociais, nós vamos para a base. Então nós temos que manter essa articulação permanente, constante com essa base (comunidade, realidade). A academia também deveria ser "a base", uma outra base, onde nós vamos discutir e depois podemos levar novamente para a comunidade-base. Então é nessa dialética que se deveria articular e se mover. Para mim, talvez, metodologicamente poderia ser assim, e é um pouco isso que 
estou a fazer. Eu tento estabelecer esse diálogo, já faz parte da minha índole, da minha maneira de ser, gosto de estar na base, na comunidade e trazer o pensamento, sentimentos, desenvolver pontes: eu quero criar pontes.

O que você pensa sobre a categoria "feminismo", ela é útil em Moçambique e em África, ou seria preciso pensar outra categoria, outro conceito?

Esmeralda - Eu vou voltar ao meu estudo com a colega francesa que sempre se dizia feminista. E eu nunca me identifiquei como feminista. Nunca disse "eu sou feminista", mas acredito e comungo alguns dos princípios feministas, da emancipação, da liberdade, do respeito, dos direitos, do espaço, do poder, da luta que nós temos que fazer para a afirmação destes princípios. Eu bebi isso na minha família. Na minha casa. Mas nunca usei o termo em si, nunca estive preparada para ter que me afirmar como tal, antes de ir ao campo, nesse estudo sobre gênero e sexualidade. Como disse antes, não tinha tido formação teórica sobre o feminismo, mas na vida quotidiana, sempre tive sensibilidade e atenção sobre a qualidade e dinâmicas das relações entre homens e mulheres, e sobre os indivíduos em geral, conhecia teóricas feministas, ouvia falar com minha mãe, mas eu já tinha formação universitária.

\section{De que feministas sua mãe falava?}

Esmeralda - Da Ângela Davis, da Simone de Beauvoir.

\section{Que incrível.}

Esmeralda - Incrível! Incrível!

\section{Tu dizias da tua formação...}

Esmeralda - Nalgum momento, com a minha colega, quando nós ouvíamos outras mulheres, enquanto estávamos sentadas, elas falaram como é que elas fazem, o que fazem com os seus corpos. Aquelas nuances, a gente não sabe, que os homens não sabem (fingem de não saber): "ah, mas os homens sabem que nós fazemos isso", mas isso é um mundo de mulheres. Perguntei a ela: "tu não sentiste a forma como elas falam, como se sentem como se tivessem poder?" Pois ela disse "yah" [sim]. Então ela mudou a visão. Ela já tinha feito outros estudos em Moçambique, em outras regiões e dizia que isso é subordinação feminina, e ela mudou, abriu a visão, isto é interessante, abriu. Rompeu um paradigma, que eu não tinha. Quer dizer, eu tinha algum conhecimento e maior abertura 
para captar outras experiências e nuances, porque não estava formatada naquela perspectiva feminista.

\section{Você não estava naquele enquadramento...}

Esmeralda - Exatamente. Então, chamei atenção à existência de espaços de poder feminino. Eu disse, "mas isto aqui é um espaço de poder interessante", e começamos a refletir sobre isso efetivamente. Está um pouco em linha com o que a Signe Arnfred traz nos seus trabalhos. Então eu penso que faz sentido nós rompermos com as categorizações. Cada vez mais que estou a crescer sinto-me mais incomodada com essas categorias: feminismo, masculinidade, em termos de oposições... Eu estou..., não sei como explicar, mas primo mais pelo respeito pelas pessoas, pelos indivíduos. Que sejam mulheres, que sejam homens. Esta definição de mulher, nós estamos a ver que às vezes não faz sentido chamar de mulher, porque limita, é redutivo.... Continuamos a perpetuar essas lógicas binárias de chamar mulheres $\mathrm{x}$ homens, em vez de chamar de indivíduos, pois me parece que "indivíduos" é uma categoria que contempla seres independentemente do sexo, raça... Mais uma vez nós chamamos mulher e homem, como chamamos branco e preto, que leva à raça. Eu acho que já não me satisfaz, reduz, porque os indivíduos têm e são muito mais. Não sei se estou a crescer em termos intelectuais e físicos, também, que me levam ao inconformismo. A propósito disso, vou terminar fazendo referência a uma categoria da feminista africana, Oyèrónkẹ́ Oyěwùmí. Ela fala mais do conceito de gênero em termos de senhoridade. E sobre esse aspecto, ligado a mim, ao meu sentimento, que já estou ficando cada vez mais incomodada com essas categorias. Há o fato de que nos relacionamos com indivíduos, com pessoas e já estamos educados a dizer "é mulher, é homem", mas eu já não sei, às vezes quem é homem e quem é mulher e o que é ser homem e mulher? Nas culturas do Sul de Moçambique (entre os Changana) o termo sungukati, que designa a mulher madura, crescida, na menopausa ou a caminho, e que quando passa para essa outra fase (biológica) têm quase os mesmos direitos (sociais) que os homens. Por exemplo, participar dos eventos que normalmente são dos homens. Essas mulheres são as que têm um segredo da família, da casa, até a própria palavra significa kati = casa, do lar, sungu = amarrar. É aquela que tem maturidade, é uma sábia, é uma pessoa que tem conhecimento, e que depois tem um poder. Ai com sungukati já não há problema de gênero, de masculino ou feminino, de ser percebido gênero em termos de relações e diferença sexual. Já não há, é pessoa, é um estatuto. Acho que estou ficando sungukati...(risos). 
E como foi sua experiência nesses processos, sendo uma local e também circulando no global, como vivenciou essas tradições e ritos?

Esmeralda - Foi interessante, porque diziam que se faz o alongamento dos lábios na idade entre 8 e 12 anos, pois os tecidos estão mais flexíveis e a dor é mais suportada. Portanto, é quase como uma imposição. Tem o fator da elasticidade, mas as mulheres disseram que tem um espaço para aquelas mulheres que não o fizeram naquela idade, mas que podem fazer na idade adulta, com outros procedimentos, com outros produtos, tem um pouco mais de risco, é quase como se fosse uma penalização, vamos dizer assim, por não ter feito no devido momento. Mas a penalização tu sentiste ao longo desse tempo, ou porque descobriu que tem essa prática, ou o companheiro, da mesma cultura, considera importante para a performance sexual e a estética corporal, então vais fazer. Ou por tua iniciativa dizes "eu quero aumentar o prazer e isto é interessante, vou fazer". É como cortar o cabelo e depois deixar o cabelo longo. Na perspectiva dos atores envolvidos na escola de iniciação à sexualidade, algumas pensam que se poderia retardar o início à prática, deixar um pouco mais de tempo para as meninas, a partir de uma certa idade quando estão mais conscientes. Esse é um dos pontos críticos na lógica dos direitos humanos, porque não há um consentimento das raparigas para dizerem "eu quero", ou não, e ai prevalece a obrigatoriedade.

\section{REFERÊNCIAS}

BAGNOL, Brigitte e MARIANO, Esmeralda. Cuidados consigo mesma, sexualidade e erotismo na Província de Tete, Moçambique. Physis vol.19 no. 2, Rio de Janeiro, 2009. Disponível em [https://www.scielo.br/scielo.php?script=sci_arttext\&pid=S0103$73312009000200008 \&$ Ing=pt\&tlng=pt]. Acesso em 22 mai. 2020].

GASPARETTO, Vera F. GASPARETTO, Vera F. Corredor de Saberes: vavasati vatinhenha (mulheres heroínas) e redes de mulheres e feministas em Moçambique. Tese de Doutorado. Orientadora: Luzinete Simões Minella. Coorientadora: Isabel Maria Casimiro. Universidade Federal de Santa Catarina, Centro de Filosofia e Ciências Humanas. Programa de Pós Graduação Interdisciplinar em Ciências Humanas. Florianópolis, 2019.

MARIANO, Esmeralda. Ser antropóloga entre local e global. Revista Antropologia, São Paulo, Online), v. 60 n. 3: 65-88, USP, 2017.

PIMENTA, Denise e MOUTINHO, Laura. Um encontro com Esmeralda Mariano: reflexões sobre o fazer antropológico em Moçambique e alhures - entrevista com a antropóloga Esmeralda Mariano, professora da Universidade Eduardo Mondlane 
(Maputo - Moçambique). Rev. Cadernos de Campo | Araraquara | n. 23 | p. 13-24 | jul./dez. 2017.

\section{NOTAS}

Vera Fátima Gasparetto

Doutora em Ciências Humanas pelo Programa de Pós-Graduação Interdisciplinar em Ciências Humanas - PPGICH, da Universidade Federal de Santa Catarina, UFSC, Florianópolis, Brasil

gasparettovera@yahoo.com.br

(1) http://orcid.org/0000-0002-3865-0549

Endereço de correspondência do principal autor

Rua Graciliano Manoel Gomes, 1584, casa 1 - 88058-200 - Florianópolis - SC

AGRADECIMENTOS

Esmeralda Mariano, que gentilmente revisou o material.

\section{CONTRIBUIÇÃO DE AUTORIA}

Concepção e elaboração do manuscrito: V.F. Gasparetto

Coleta de dados: V.F. Gasparetto

Análise de dados: não se aplica

Discussão dos resultados: Não se aplica

Revisão e aprovação: E. Mariano

Caso necessário veja outros papéis em: https://casrai.org/credit/

CONJUNTO DE DADOS DE PESQUISA

FINANCIAMENTO

PDSE/Capes

\section{CONSENTIMENTO DE USO DE IMAGEM}

Não se aplica

\section{APROVAÇÃO DE COMITÊ DE ÉTICA EM PESQUISA}

Não se aplica

\section{CONFLITO DE INTERESSES}

Não se aplica

\section{LICENÇA DE USO}

Os autores cedem à Revista Internacional Interdisciplinar INTERthesis os direitos exclusivos de primeira publicação, com o trabalho simultaneamente licenciado sob a Licença Creative Commons Attribution (CC BY) 4.0 International. Esta licença permite que terceiros remixem, adaptem e criem a partir do trabalho publicado, atribuindo o devido crédito de autoria e publicação inicial neste periódico. Os autores têm autorização para assumir contratos adicionais separadamente, para distribuição não exclusiva da versão do trabalho publicada neste periódico (ex.: publicar em repositório institucional, em site pessoal, publicar uma tradução, ou como capítulo de livro), com reconhecimento de autoria e publicação inicial neste periódico.

\section{PUBLISHER}

Universidade Federal de Santa Catarina. Programa de Pós-graduação Interdisciplinar em Ciências Humanas. Publicação no Portal de Periódicos UFSC. As ideias expressadas neste artigo são de responsabilidade de seus autores, não representando, necessariamente, a opinião dos editores ou da universidade.

\section{EDITORES}

Javier Ignacio Vernal e Silmara Cimbalista

\section{HISTÓRICO}

Recebido em: 28-06-2020 - Aprovado em: 09-10-2020 - Publicado em: 16-11-2020 